\title{
Offshore wind competitiveness in mature markets without subsidy
}

\author{
Malte Jansen ${ }^{1}$, lain Staffell ${ }^{1}$, Lena Kitzing ${ }^{2}$, Sylvain Quoilin ${ }^{3}$, \\ Edwin Wiggelinkhuizen ${ }^{4}$, Bernard Bulder ${ }^{4}$, legor Riepin ${ }^{5}$, Felix Müsgens ${ }^{5}$
}

${ }^{1}$ Centre for Environmental Policy, Imperial College London, United Kingdom

${ }^{2}$ Energy Economics and Regulation Group, DTU Technical University of Denmark, Denmark

${ }^{3}$ Smart Energy Systems Research Unit, KU Leuven, Belgium

${ }^{4}$ TNO, Netherlands

${ }^{5}$ Chair of Energy Economics, BTU Cottbus-Senftenberg, Germany

\section{Abstract}

Offshore wind energy development has been driven by government support schemes, but recent cost reductions raise the prospect of offshore wind becoming cheaper than conventional generation. Many countries use auctions to provide financial support, but differences in auction design make their results difficult to compare. Here we harmonise the auction results from five countries based on their design features, showing that offshore wind can be considered commercially competitive in mature markets. Between 2015 and 2019, the price paid for offshore wind across northern Europe has fallen by $11.9 \pm 1.6 \%$ per year. The bids received in 2019 translate to an average price of $€ 51 \pm 3 / \mathrm{MWh}$, and substantially different auction designs have received comparably low bids. The level of subsidy implied by auction results depends on future power prices, but projects in Germany and Netherlands are already subsidy-free, and it appears likely that in 2019 the UK has auctioned the world's first negativesubsidy offshore wind farm. 


\section{Main Text}

Decarbonising energy systems is a global necessity. Electricity from renewable energy sources (RES) will be crucial for the transformation. Together with photovoltaics and onshore wind, offshore wind energy has become a major contributor of renewable electricity in Europe. With growth rates exceeding $35 \%$ p.a. for the last five years ${ }^{1}$, global installed capacity reached $28 \mathrm{GW}$ by the end of 2019. Over $127 \mathrm{GW}$ is forecasted by 2040 under the IEA's most conservative scenario ${ }^{2}$ and the European Commission has announced its ambition between $250 \mathrm{GW}$ and $450 \mathrm{GW}$ of offshore wind in 2050 for Europe alone ${ }^{3}$. Global technical potentials exceed 10,000 GW of capacity and 5,000 TWh annual production in each of Europe, America and $\mathrm{Asia}^{4,5}$.

This historic increase came at a cost. Offshore wind energy was significantly more expensive than conventional generation and even among options for decarbonisation ${ }^{6,7}$. Recently, the technology has experienced rapid cost reductions, which have been widely discussed in the media and consultancy reports ${ }^{8-10}$, with some speculating that subsidy-free offshore wind was already achieved. As with the rapid cost reductions in solar photovoltaics ${ }^{11}$ and energy

15 storage ${ }^{12}$, the pace of offshore wind cost reductions has proceeded more rapidly than was widely anticipated, in contrast to increasing capital costs during earlier stages of development ${ }^{13-16}$. For example, Wiser et al. ${ }^{17}$ used an expert survey in 2016 to forecast cost reductions for wind power, and the prices received in recent auctions have already fallen below the expectations for 2050 .

Controversy remains around how close offshore wind power is to economic competitiveness against other decarbonisation options ${ }^{18,19}$. NREL compared auction results from the Netherlands, United Kingdom and Denmark by adjusting values to account for grid connection, development costs and contract lengths ${ }^{20}$. A transparent methodology was not provided though, which limits the replicability of results and the ability to update data in this fast-paced industry. The IEA Wind TCP Task 26 has compared country-specific impacts on the levelised cost of electricity $(\mathrm{LCOE})^{21}$, comprehensively covering the costs of offshore wind. Whilst the publications provide valuable background, they do not explain the bids and the pace of the underlying cost reduction. Both issues are addressed in this paper.

Competitiveness can be measured by comparing costs (usually LCOE) to other technologies or to wholesale market prices, as an aggregated measure of competition in the system ${ }^{21,22}$. 
However, actual LCOE data are only available in selected countries because of their commercial value and sensitivity ${ }^{23,24}$ and these can be misrepresentative ${ }^{25}$, and so costs must be estimated. For offshore wind, estimates of investors' expected LCOE can be derived from auction results, and data on successful bids are often published openly. Although bids should correlate with costs, they cannot be directly translated, as information on expected revenues from wind power projects is unavailable.

Several important differences exist between auction designs, including the length of support, whether it rises with inflation, optionality in building the project, and whether development costs are included. Most critically, the contracts for differences (CfDs) used for remuneration can be categorised as 1-sided (providing a lower-bound price below which revenues from the wind farm cannot fall) or 2-sided (providing a fixed price with both lower and upper bound). For this reason, a bid of $€ 20 / \mathrm{MWh}$ in Germany may provide more financial revenue to a wind farm developer than a bid of $£ 50 / \mathrm{MWh}$ in the UK.

We harmonise the winning bids from 41 wind farms across auctions in five European countries from 2005 to 2019, accounting for the main features of each auction. Wind farms were selected based solely on their payment allocation scheme, i.e. only wind farms that were auctioned. All offshore wind technologies were considered, as were all countries that had held at least two auction rounds at the time of writing (the minimum required to detect a trend). These five countries represented $77 \%$ of global offshore wind capacity, and the only other country to hold more than $1 \%$ of global capacity was China, which was not included as it had only auctioned a single offshore wind farm at the time of writing ${ }^{1}$. This analysis provides two measures: the expected revenues (in $€_{2019}$ per $\mathrm{MWh}$ ) for each wind farm, which we then compare with potential future wholesale market prices to estimate the effective subsidy, and thus the financial competitiveness of each wind farm. We aggregate data on auction settings and results, showing that current offshore wind technologies at good sites in mature markets have implied prices of less than $€ 50 / \mathrm{MWh}$, which is likely to be subsidy-free or negativesubsidy depending on future power prices.

\section{Offshore wind auctions in Europe}

Five countries in Europe have held auctions for offshore wind capacity. In total, 17 auctions have been held, bringing forth over $20 \mathrm{GW}$ of capacity. The evolution of winning bids across these auctions is summarised in Figure 1. This does not reveal a clear trend and is confounded 
by several bids of $€ 0$ (made into 1-sided CfD auctions) beginning in 2017. While a declining trend can be observed, this reveals as much about the heterogeneity amongst auction designs as it does about the reduction in wind farm costs.

Figure 1: Raw bids received by auctions for new offshore wind capacity in five European countries over the past eight years. Points show the date that auctions were announced, and are converted from local currency to $€_{2019}$.

All auctions for offshore wind in Europe are designed so that the wind farm operator receives a guaranteed price for a certain predefined period. This so-called strike price or bid price closes the gap between the market reference price (i.e. wholesale electricity prices) and a guaranteed price. However, the exact arrangements of the payments differ between countries, and the specific design of the support scheme gives rise to significant differences in the bids received, and so must be accounted for when comparing bids across different schemes. Clarification on auction design features and their influence can be found in ${ }^{26-29}$.

Several differences in implementation exist. (1) The choice of remuneration mechanism, specifically the allocation of market upside. One-sided CfDs usually pay when wholesale prices are below bid prices but do not demand money if wholesale prices are above bid prices. With two-sided CfDs, investors must compensate for wholesale price revenues above bid prices. Further explanation can be found in Supplementary Note 1. (2) Defining the support duration based on a fixed time period (years) or by the total support volume (TWh). (3) Accounting for indexation, which defines whether the guaranteed price is adjusted for inflation, choice of inflation index and base year for indexation. (4) Choice of market reference price used as the basis for comparison to the guaranteed price (e.g. hourly, daily, monthly average). (5) Floors of market price below which no support is being paid out (e.g. at negative market prices for several consecutive hours). (6) The allocation of land lease costs, (7) grid connection costs and (8) site development costs. (9) The option to capture alternative revenue streams (e.g. ancillary services), and (10) penalties for non-fulfilment of the contract, which could mean bids are conceived as options to build, not necessarily reflecting realistic cost estimates in all cases.

The auction schemes vary considerably across the five countries we consider, as summarised in Table 1. All auctions provide remuneration based on produced energy (i.e. per kWh), but 
other design aspects are not comparable between auction schemes. Further details are given in Supplementary Data and Supplementary Table 1. An overview of each country's auction design and their differences is given in Supplementary Note 2.

Table 1: Main characteristics of the auction systems for offshore wind capacity in five European countries. Full details about each wind farm in these auctions are provided in Supplementary Data and Supplementary Table 1. Two bids from German wind farms were undisclosed ${ }^{35}$ and thus not further analysed. Denmark implements a new auction design for each round and support length is based on energy production. For more information on the auction design of each country refer to Supplementary Note 2.

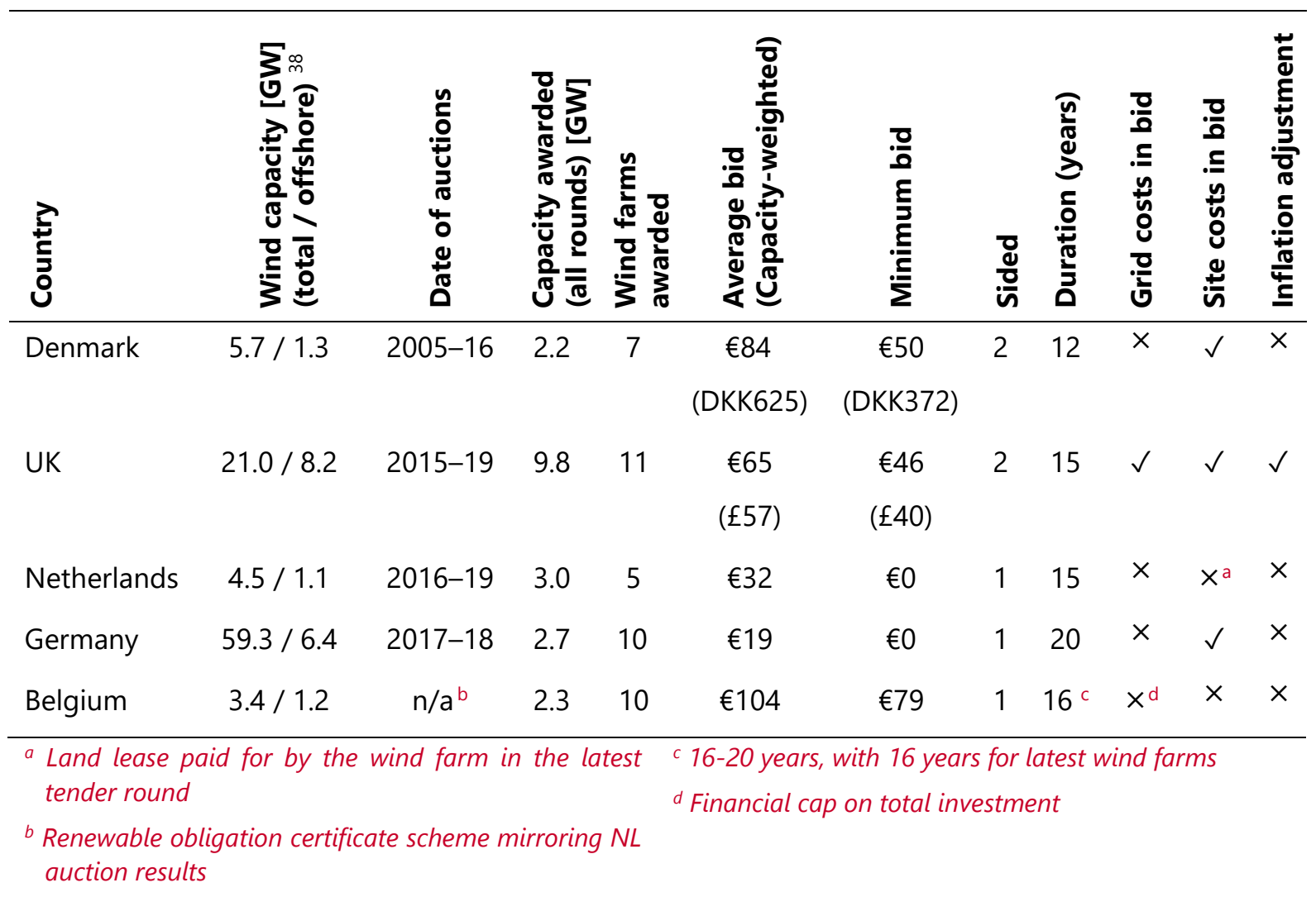

\section{Harmonisation of expected revenues}

The significant differences we identify in auction and product design across countries directly influence the costs and/or revenues of projects, and thus influence the bids received. The winning bids in European auctions for offshore wind were harmonised using a monthly cashflow analysis, accounting for the most significant factors identified in the previous chapter (see 
Methods). We define the 'harmonised expected revenue' as the discounted average revenue per MWh of electricity generated over the lifetime of the project. This gives the equivalent bid that would be offered into a support scheme with a 2-sided CfD with 25-year support duration, indexation to inflation, and site development costs paid by investors.

The harmonised expected revenue incorporates all the money a wind farm can expect to earn over its lifetime, including revenues for later in the project's lifetime when support has run out. It is therefore complementary to the widely-used LCOE metric, referring to revenue rather than cost. It could therefore be a proxy to LCOE in perfectly competitive markets. The details for each wind farm that were used to harmonise expected revenue, including key dates and technical specification, are given in Supplementary Data and Supplementary Table 1.

Figure 2: Harmonised expected revenues for each offshore wind farm auctioned in Europe. Each symbol shows the planned start date of operation against the harmonised expected revenue. Lines show the lognormal regression of expected revenue against time across all countries, covering all bids and the most recent bids (since 2015). Shaded areas depict \pm 1 standard deviation on each regression. Wholesale electricity prices are assumed to remain constant in real terms when deriving revenue beyond the end of the support duration. Other price scenarios are shown in Supplementary Figures $1 \& 2$.

Comparing the harmonised expected revenues in Figure 2 with the raw bids reveals substantial differences: The raw bids range $€$ 0-150 /MWh, whereas expected revenues are $€ 50-150 / M W h$, with wind farms due after 2020 converging towards a range of $€ 50-70 / \mathrm{MWh}$. From this analysis we cannot identify one country that consistently creates lower bids than others, despite varying site conditions, auction criteria and level of competition. A capacity-weighted logarithmic regression through all auction results yields a reduction in the harmonised revenue requirement of $5.8 \%$ per year, with a standard error of the regression of $\pm 1.1 \%$. When considering the more recent auctions, with a start date from 2015 onwards, this rate increases to $11.9 \pm 1.6 \%$ per year. Results for individual countries are presented in Supplementary Table 2 and Supplementary Figure 2. A logarithmic fit was chosen to ensure that regression results cannot fall below zero. The increased rate of cost reduction indicates that auctions may have helped to improve efficiency in the offshore wind industry. 
Large differences between auction date, final investment decision (FID) and planned commencement of operation can be noted. For some zero bids in Germany, more than five years lie between the auction result and commencement of operation, whereas several wind farms in the UK made FID on the day of winning the auction or shortly after. This gives German wind farm developers more time for turbine costs to decrease and lets the bids appear more in line with each other.

Figure 2 shows that harmonised expected revenues for several projects have fallen below $€ 50 / \mathrm{MWh}$. This locates offshore wind towards the lower end of estimated LCOE for fossil generators ${ }^{22}$. Such comparison must be caveated though, as these revenues will only reflect costs in perfectly competitive markets, and cost comparisons between variable renewables and dispatchable fossil-fuelled generators are subject to ongoing debate around integration $\operatorname{costs}^{30-32}$.

The harmonised expected revenue of most projects depends on the future development of wholesale prices. First, wholesale prices are directly received by projects under 1-sided CfDs provided they are above the bid. Second, with an assumed technical lifetime of 25 years, all projects are expected to sell their output on the wholesale market after their auction remuneration expires. Medium- to long-term wholesale prices are therefore of particular importance to these results, but at the same time, they are highly uncertain. This is not only an academic exercise but an issue that the bidding companies must deal with, and one that the energy industry is, in general, familiar with. Estimates can be made using electricity market models to quantify the future energy system, but these depend on numerous uncertain assumptions, such as the future $\mathrm{CO}_{2}$ allowance price. The fact that we find similar revenues for wind farms across several countries in the future would, however, indicate that several bidders have arrived at comparable outlooks on the future power prices.

The results in Supplementary Figure 2 consider the sensitivity of these results to the future trajectory of wholesale power prices. We explore this uncertainty by presenting a range of prices derived from independent sources. First, we consider the European Commission's 2016 Reference Scenario, and scale projected prices from 50-150\%. This accounts for structural changes in the electricity market (e.g. increased penetration of renewables and higher carbon prices), but is fundamentally a theoretical modelling exercise. To complement it, we take the average power prices from 2004-2018 in each country and apply a constant real-term annual 
growth rate from $-2 \%$ to $+2 \%$, which more than spans the range of historical price growth seen in these countries.

We argue that the long-term prices are probably the better indicator. The EU 2016 Reference Scenario prices are set to double electricity prices in many countries between 2010 and 2020 and therefore we exercise caution using this price forecast alone. We provide the results of all described price scenarios in Supplementary Figure 2 as well as the means to test other price trajectories using Supplementary Software 1. From this assessment, we observe the large influence that the power price has on the harmonised revenues, an investigation that each bidder will have to face individually.

\section{Moving towards subsidy-free offshore wind}

Figure 3: Effective subsidy for each offshore wind farm auctioned in Europe. Panel a assumes grid connection costs should be paid for by the developer and thus considered as part of the wind farm. Panel $b$ assumes these should be socialised and considered as part of the overall grid infrastructure. Each marker shows the effective subsidy for each wind farm at the planned date of operation. Lines show the linear regression of effective subsidy against time across all countries, covering all bids, and recent bids from 2015 onwards. Shaded areas depict \pm 1 standard deviation on each regression. Wholesale electricity prices are assumed to remain constant in real terms when calculating support level from each CFD. Other price scenarios are shown in Supplementary Figure 3.

The harmonised expected revenues (including the support payments expected under each wind farm's CfD contract) can be compared to the expected revenues that would be generated on the wholesale market alone (as if each wind farm were a purely merchant project). The difference between these allows us to derive the effective subsidy that is being paid to each farm, as shown in Figure 3. This is the difference between the discounted income stream due to the RES support payments. If the expected harmonised bid is equal to the expected wholesale market price, the effective subsidy is zero and the project is subsidy-free. These subsidies are the amount of money that will have to be refinanced through the RES support scheme. 
This study does not deal with the question of whether grid construction costs should be paid by developers (the allocation-by-cause principle) or be paid by society (socialised as part of a country's infrastructure investment). Figure 3 therefore presents both versions, keeping in mind that grid costs account for $€ 13 / \mathrm{MWh}$ on average. It must be noted that most countries have chosen the latter option, and their funding models for grid infrastructure differ greatly. In the UK, socialised grid costs are borne jointly by generators and demand through transmission charges for the transmission grid whereas offshore connection is paid by the wind farm only. Germany recovers grid charges (including for new offshore wind farms) through final consumer bills only. Offshore grid connection costs remain a key uncertainty despite efforts to gather data ${ }^{23,33,34}$ and model $^{35}$ these costs for each wind farm (given in Supplementary Data and Supplementary Table 1).

With socialised grid connection costs, subsidies have reached $-€ 12$ /MWh for the latest UK auction, with a large cluster between $-€ 10 / M W h$ and $€ 20 / M W h$. This implies that several wind farms could expect to earn less money under the RES support scheme than under wholesale market terms alone (even with expected revenue cannibalisation effects). With the grid costs being paid for by the developer, the lowest effective subsidy is at $€ 2 / \mathrm{MWh}$ when assuming wholesale power prices grow at 0\% p.a. in real terms. Even slight growth in market prices (above $0.28 \%$ p.a.) means that the cheapest wind farms are therefore subsidy-free.

It can make sense for companies to forgo revenues in exchange for their predictability. The funding from the RES support scheme minimises risk in several ways. Most notably, exposure to future market prices is reduced, which in turn can reduce the cost of financing these multi-billion Euro projects, allowing for a lower LCOE in the first place ${ }^{36}$. Secondly, using the RES support scheme in all cases comes with monetary (e.g. socialised grid connection) and non-monetary privileges (e.g. site allocation, consenting and planning) thus limiting the pre-development costs for each project.

Across all auctions and with grid support paid for by the developer, the expected support is falling by $€ 5.30 \pm 1.00 / \mathrm{MWh}$ per year. Considering only auction results from the last 5 years, the support has been falling even more dramatically, by $€ 10.20 \pm 1.60 / \mathrm{MWh}$ per year, implying that offshore wind farms built from 2025 onwards will on average be subsidy-free if these cost reduction rates continue. The rates of reduction are virtually identical if grid costs are socialised, with $€ 5.20 \pm 0.90 / \mathrm{MWh}$ (all auctions) and $€ 10.20 \pm 1.50 / \mathrm{MWh}$ (2015-2019) per year. 
This suggests that the era of subsidy-free wind farms will begin in 2023 based on recent auctions, or in 2024 when all data are considered.

\section{Sensitivity to future power prices}

To analyse the significance of future price developments for subsidy-free offshore wind, we vary future wholesale price assumptions and calculate resulting effective subsidies. Figure 4 summarises how the effective subsidies are affected by wholesale electricity prices changing by between $-2.5 \%$ and $+2.5 \%$ per annum in real terms.

Countries which offer 2-sided CfDs (UK, Belgium and Denmark) show a greater sensitivity to future wholesale prices, as higher reference prices can see farm developers paying money back to society. The minimum bids received in Germany and the Netherlands show no sensitivity to power prices (horizontal lines in Figure 4 right panels). These 1-sided $€ 0 / \mathrm{MWh}$ bids will only see support paid if wholesale prices turn negative, which is only expected in a minority of hours per year (see Methods). If these wind farms ought to pay for grid connections, this would be added onto the zero bid (Figure 4, top-right). It is noteworthy that the UK with its latest auction appears to offer the lowest support payment for any wind farm, with an effective subsidy of less than $€ 12 / M W h$, which in part is due to the implementation of a two-sided CfD whilst power prices are predicted to increase by the government ${ }^{37}$.

Figure 4: Effective subsidy given to offshore wind farms as a function of future real-terms growth in wholesale power prices. The panels show four variants, considering the average bid (panels a and c) and minimum bid (panels b and d) received in each country, assuming grid connection costs should be paid by the developer (panels $a$ and b) or should be socialised (panels $c$ and d). Circles on each line indicate the average real-terms growth in wholesale power between 2004 and 2018.

The results of the latest UK auctions indicate that if wholesale prices continue to see moderate growth of above $0.3 \%$ p.a. (which is below the historical rates) then these farms will receive negative subsidy: and will be the first to pay money back to society. If grid construction costs are assumed to be socialised, UK offshore wind farms would be subsidy-free even if power prices fell by more than $1.5 \%$ p.a. in real terms. Wind farms in Germany and the Netherlands 
are subsidy-free under any price scenario, whereas Belgian are trailing the in terms of effective subsidy. The last auction in Denmark took place in November 2016, resulting in a comparatively high effective subsidy, but still showing comparable cost progression to the industry as a whole.

\section{Discussion \& Conclusions}

The era of 'subsidy-free' offshore wind turbines has begun. This conclusion is founded on zero bids in the Netherlands and Germany which effectively track wholesale power prices, and bids around $£ 40 / \mathrm{MWh}$ in the UK which will be below future wholesale prices if historical growth rates are maintained. Recent projects in the Netherlands have bid €0 /MWh and will pay land lease, indicating that offshore wind is at the point where it will likely to pay money back to the system.

Despite significant variations in auction design, we find that once bids are harmonised the expected lifetime revenues of wind farms are homogenous across countries, without specific outliers that would be attributable to the auction design. This implies that policy makers have managed to create auction designs which fairly reflect the actual costs of developing offshore wind farms, and that the specific auction design is not particularly influential on the outcome. This finding could aid in designing the upcoming auction schemes for offshore wind globally. It also opens the door to further questions, such as whether auctions are suitable policy instrument for driving down costs in less mature technologies such as wave, tidal, and floating offshore wind energy. The study does not unveil whether policymakers should discontinue support for renewables once price-parity is achieved, as the revenue stabilisation offered by $\mathrm{CfDs}$ has been instrumental in making this possible for offshore wind ${ }^{2}$.

Harmonising bids into expected revenues creates a proxy for the actual costs of offshore wind which closely relates to the levelised cost of electricity (LCOE) plus profit for the company. We show that wind farm costs are decreasing across Europe in a uniform fashion, having undercut the $€ 50 / M W h$ threshold recently. This makes offshore wind a competitive way to produce electricity and is an extraordinary story of success for a relatively young industry. It is possible that future wind farm developers will aim to build 'merchant' offshore wind farms without financial support, completely free of government support. Development costs may however rise as wind farms move to less favourable locations or to less mature technologies. 
There are several reasons why the harmonised expected revenues we report may diverge from underlying costs. Auction results can be seen as an 'option to build' which need not be realised if costs do not fall sufficiently ${ }^{35}$. However, the final investment decision (FID) has already been taken for some recent bids (including the cheapest ones), including one on the day of the auction result (see Supplementary Data and Supplementary Table 1). We interpret these tangible financial commitments as a sign of developers' intent to go forward with the awarded bids. The breadth and heterogeneity of our sample (41 projects in different countries and auction rules) also suggests that such 'option bidding' effects are unlikely.

The presence of market power could also distort revenues away from underlying costs in either direction. If the industry is going through a shakeout period, investors may bid below cost to deter new entrants from providing competition, accepting short-term losses in return for gaining market share and higher long-term profits. This would mean true costs were above the harmonised expected revenues we report. Alternatively, an oligopoly of large developers could exploit the lack of competition to artificially inflate auction prices. This would mean true costs lie below our harmonised expected revenue, and that offshore wind was more competitive than our analysis suggests.

To facilitate market access, electricity generated from offshore wind is often sold through power purchase agreements (PPAs), especially in the UK. PPAs provide long-term revenue stability and offtaker risks are assumed by a counterparty. These could yield agreed prices below the wind-weighted average wholesale price used here, if for example limited competition between providers facilitated excess profits. This would lower expected revenues, suggesting that offshore wind is cheaper than our results indicate. Evidence on the discounts offered in PPAs is not publicly available, so we cannot establish whether they are reflective of the underlying revenue cannibalisation found across the investigated countries.

Policymakers can take the rapid price decreases shown here as evidence that offshore wind will deliver in the future as a low-cost and low-carbon technology. Hence, the initial spending made on support schemes has been successful in helping to create a new industry. This opens up questions around the next steps to support the further rollout of offshore wind. This will likely entail designing schemes which move away from support payments and instead focus on planning issues, market integration, grid connection and ease of access to financing.

Building on the story of success, policymakers may want to extend their attention to support less mature technologies such as floating offshore wind, which would allow access to deeper 
waters with higher wind speeds. These technologies are currently at a less mature stage but may prove vital in harnessing the world's best wind resources ${ }^{2}$.

Our findings are derived from wind farms in Europe, but hold relevance for other parts of the world. Europe has been at the forefront of offshore wind due to its favourable conditions of relatively shallow waters and high wind speeds. This enabled cost-efficient monopile foundations to be used in most, but not all offshore wind projects. One-fifth of the capacity we consider uses jacket or gravity-based foundations. Regions of Asia and North America also benefit from shallow waters ${ }^{2}$, and could expect some of the learning of Europe (e.g. turbine size increase, construction techniques, financing) to play a key role in achieving similar results. The rates of price reduction found here may prove equally applicable to other world regions, and to other foundation types if they achieve comparable scale up, albeit from a higher starting price level. Regions that are yet to develop a supply chain and innovation system for offshore wind energy may require longer for these technologies to become subsidy-free.

As decarbonisation of the world's electricity systems gains traction, attention must be given to the issues of balancing and flexibility, and to the decarbonisation of heat, transport and industrial applications. With offshore wind at competitive prices, numerous sector-coupling applications are coming into reach that could not have been imagined as cost-competitive just a decade ago. 


\section{General principle}

Both auction and product design vary significantly between different countries. We identified major differences from a review of government literature and present these in Supplementary Data and Supplementary Table 1. Many of the differences directly influence the costs and/or revenues of projects, and thus influence the bids. This is obvious for the support duration but also e.g. for one-sided vs. two-sided support schemes where the former has an implied option to profit in the event of future wholesale price increases. Consequently, one-sided CfDs require lower bids to make projects profitable.

The differences between auction designs were accounted for by developing a methodology to harmonise the winning bids in European auctions for offshore wind. Our harmonization accounts for the most significant factors identified in Table 1. The bids are harmonised using a monthly cash-flow analysis, which addresses seasonal variation in wind capacity factors and allows volume-based support schemes to expire part-way through a year. Hence, we define the 'harmonised expected revenue' as the (discounted) average revenue per MWh of electricity generated over the lifetime of the project. This can be interpreted as the bid that would give an equivalent NPV over the project life if it were offered into a hypothetical auction that offered a 2-sided CFD with 25-year duration, indexed with inflation. On this basis, we can compare the bids (and the implied expected revenues) over each wind farm's entire lifetime, and e.g. include revenues for later in the project's lifetime when support has run out. Details on each wind farm were sourced from developer and manufacturer websites and professional databases (e.g. 4COffshore) as well as renewables and offshore wind news outlets, primarily ${ }^{39-43}$.

The following sections detail how we adjust each bid's strike prices to obtain harmonised expected revenue. Each adjustment changes the monthly cash-flow, which results in monthly payments to the wind farm from the market and the 'effective' payments from the RES support scheme. The payment over the lifetime of the project is then aggregated. This yields the average payment per MWh received for the total (supported) payments. We also calculate the payments which would have resulted if the electricity would have been sold exclusively on the wholesale market. Finally, we calculate the difference between both, representing the actual average subsidy paid. 


\section{Harmonising length of payments}

Support durations vary between projects. For most projects, legislation specifies an explicit time duration $d_{s}$. For the Danish projects with an energy-based limit, we calculated the resulting support duration $d_{s, D K}$ as follows:

$$
d_{s, D K}=\frac{E_{s}}{P_{\text {inst }} * h_{y} * C F}
$$

With

$$
\begin{array}{ll}
d_{\text {S.DK }} & \text { Support duration for Denmark } \\
E_{S}: & \text { Supported Energy } \\
P_{\text {inst }}: & \text { Installed Capacity } \\
h_{y}: & \text { Hour in one year } \\
C F & \text { Capacity factor }
\end{array}
$$

The capacity factor $C F$ is estimated using the Renewables.Ninja model with the appropriate wind turbine model for each project ${ }^{44,45}$. The numbers are validated against external data points where possible ${ }^{46,47}$, and are found to be highly correlated. For projects using nextgeneration turbines we developed parametric power curves ${ }^{48}$ if these were not publicly available. While we attempt to use representative capacity factors, these have no influence on the main results presented as both harmonised revenue and expected support are normalised per MWh. They can have second-order effects due to output-dependent support duration, but this yields minimal changes.

External factors that could influence capacity factors over the farm's lifetime (such as degradation ${ }^{49,50}$, wake effects ${ }^{51}$, stilling ${ }^{52}$ or climate change ${ }^{53}$ ) are not considered as they are currently subject to much uncertainty. These could be incorporated once better understood using the cashflow models that we make available open source.

We model each wind farm's revenue over its whole lifetime, both from their strike price and the wholesale market alone. While the total lifetime of offshore wind projects is still debated, most publications estimate them between 20 and 30 years (e.g. ${ }^{54-58}$ ). Therefore, we assume that the lifetime $d_{l}$ for all projects is 25 years. This is needed to calculate the income after RES support from the auction has run out. Variations to this assumption have limited impact on results due to the effect of discounting. 


\section{Strike prices and market revenues}

As explained above, projects' annual revenues are determined either based on the strike price or based on the market price. Before we can identify which applies in any given year for any given project, we first must derive a consistent time series for both. Among other things, we normalise currencies to Euros and all values to real monetary values for the year 2019.

We assume that wind farms sell their output on the wholesale market (or at least receive payments based on the sold electricity's wholesale market value). Historic wholesale power prices are obtained from ENTSO-E and Open Power Systems Data ${ }^{59,60}$. Large uncertainties exist regarding the future of power prices, in particular as we need them more than 25 years in the future. The influence of power prices is paramount for our considerations as it affects the bids in a significant way. Obtaining consistent price forecast scenarios is challenging as the national price forecast would show inconsistencies on the input assumptions (fuel prices, $\mathrm{CO}_{2}$-emission prices, etc.).

To address the uncertainty around future power prices we choose a diversified approach. (1) The EU 2016 Reference Scenario PRIMES model provides a consistent output covering all of Europe ${ }^{61}$, which forecasts annual average power prices for every fifth year until 2050. It is to note that the prices are significantly higher than today's prices. Therefore, we multiply the prices provided with factors of $0.5,1.0$, and 1.5 to create an understanding of the impact of price variations. (2) Whilst best efforts have been made to model future power prices, we aim to mitigate the influence of modelling altogether, by using the average annual power prices to establish the long-term price variations. We use long-term prices (2004-2018) averages and assume an annual growth between $-2 \%$ and $2 \%$ in $1 \%$ steps based on this.

We can establish that the time-weighted average wholesale price for the time period $t$ is dependent on the assumed price growth $p r$. Latter can either be given in \% growth p.a., or predetermined by external inputs, such as the time series from the EU 2016 Reference Scenario.

$$
t w p_{t}=t w p_{0} * \operatorname{pr}^{\frac{t}{12}}
$$

With: $\quad t w p_{0} \quad$ time-weighted average wholesale price at project start 
However, it is well known that electricity generation from wind does not receive the average price $^{62}$. The price that offshore wind turbines will be able to realise on the market on average shall be called 'capture value' (also referred to as market value factor, see ${ }^{63}$ ). We derive a capture value is a multiplier typically below one which subtracts from the average power prices based on the linear interpolation between today's empirically determined data and the price scenarios for $2030^{64}$. The capture value $\mathrm{cr}$ is a multiplier which determines the percentage that wind can capture of the time-weighted wholesale price. It is a large source of uncertainty for wind farm developers, as it is expected to decrease over time. The results from our modelling for the country-specific average values are shown in Supplementary Table 3:

$$
\text { cr }=\frac{\sum_{h} \text { output }_{h} * \text { price }_{h}}{\sum_{h} \text { output }_{h} * \overline{p r l c e}}
$$

With:

$$
\begin{array}{ll}
\text { output }_{h} & \text { output in hour } h \\
\text { price }_{h} & \text { price in hour } h \\
\overline{\text { prlce }} & \text { time-weighted average price across all hours } \\
h & \text { hours }
\end{array}
$$

This further allows us to calculate the wind-weighted average wholesale price $w w p_{t}$ :

$$
w w p_{t}=t w p_{t} * c r_{t}
$$

Linear interpolation of the market value $\mathrm{cr}$ between today and 2030 is assumed and can be justified using the different scenarios in the UK National Grid Future Energy Scenarios annual publications ${ }^{65}$ shown in Supplementary Figure 5. The modelling shows a roughly linear relation between installed wind power and the merit-order effect. We therefore can assume a linear relationship in our assessment as well, both for the merit-order effect as well as the capture value derived from hourly time series analysis between today's data and 2030's estimation.

Determination of strike price time series is relatively straightforward: In a first step, we convert strike prices to $€$ (if applicable) using market exchange rates ${ }^{66}$. In a second step, we convert nominal values to real monetary values of 2019 using country-specific averages for the years 1998 to $2017^{67}$. The long-term inflation for all five countries was $1.65 \%$ p.a.. For the UK auctions, the strike price is adjusted by the inflation rate, which derived from the data ${ }^{67}$ and amounts to $1.89 \%$ p.a.. All available inflation data is shown in Supplementary Table 4. Note that the indexation measure used is based on the GDP deflation index rather than consumer 
price indexation, as often used by central banks. This is believed to get a more accurate representation of indexation ${ }^{68}$. The strike price $S P_{t}$ at time $t$ is by auction design either to be discounted or kept constant in real terms:

$$
S P_{t}=\frac{S P_{0}}{i r^{\frac{t}{12}}}
$$

$\begin{array}{ll}\text { With: } & \text { Strike price at project start } \\ \text { ir } & \text { Inflation rate (GDP deflation) } \\ t & \text { Time in months since project start }\end{array}$

\section{Determining revenues during support duration}

At this point, we have two normalised time series for the years of the support duration (the strike price time series and the market revenue time series, both calculated above). Which one is applicable is determined as follows:

For projects under two-sided CfDs, the strike price essentially determines a fixed payment. Hence, the relevant time series during the support duration is the strike price.

For projects under one-sided CfDs, the situation is more attractive: These projects have the right (but not the obligation) to choose the market revenues even during support duration in case they exceed the strike price. We address this optionality in two ways: first, we select the maximum of monthly strike price and market revenue as the resulting revenue during those months. This is in analogy to the option's intrinsic value. Second, the option has an additional 'time value' - reflecting the fact that the wholesale revenue described above is uncertain. It could increase - and the projects under one-sided CfDs would profit. It could also decrease, but the projects under one-sided CfDs would lose less (as they can choose not to exercise the option and sell at the strike price). Note again that in contrast to option terminology, we use "strike price" equivalent to "bid price" in this paper.

We further establish the uplift premia up as a function of the strike price $s p$. The uplift premia term describes the additional income for the generator over the market prices that is caused by capturing the upside under a 1-sided CfD. The uplift premium is a function of the ratio between strike price and wholesale market price and differs for every wind farm. 
Supplementary Figure 4 allows deriving the value for each wind farm. It is not applicable for 2-sided CfDs:

$$
u p(s p)=\frac{\sum_{h} \text { output }_{h} * \max \left\{\text { price }_{h}, s p\right\}}{\sum_{h} \text { output }_{h} * \text { price }_{h}}
$$

$\begin{array}{lll}\text { With: } & \text { output }_{h} & \text { output in hour } h \\ \text { price }_{h} & \text { price in hour } h \\ & s p & \text { strike price } \\ h & \text { hours }\end{array}$

\section{Harmonising bids}

Having calculated one specific revenue time series for each project, we then adjust these time series to reflect the (country-specific) weighted average cost of capital (WACC). This discount rate is also called the real cost of capital (over and above the inflation rate). Financing costs of wind power projects are dependent on the local funding conditions and ease of access to capital. Supplementary Table 5 presents WACC from different sources for onshore and offshore wind, with offshore wind being more expensive. The average from across these sources was used, with country-specific values ranging from $6.2-7.9 \%$, and the average across all countries being $7.3 \%$.

As all input parameters are defined now, the revenue for three different cases can be calculated. (1) Revenues without any RES support scheme payments $r 0_{t}$, (2) revenues under a 1-sided CfD $r 1_{t}$ and (3) under a 2-sided CfD $r 2_{t}$.

$$
\text { revenue }=\left\{\begin{array}{cc}
r 0_{t}=\text { output }_{t} * w w p_{t} & \text { no support } \\
r 1_{t}=r 0_{t} * u p_{t} & 1-\text { sided } C f D \\
r 2_{t}=S P_{t} & 2-\text { sided } C f D
\end{array}\right.
$$

With: $\quad r 0_{t} \quad$ Revenue at market prices

The 'harmonised expected revenues' HER for each case then results in: 


$$
H E R=\left\{\begin{array}{cc}
\sum_{t} \frac{r 0_{t}}{(1+d r)^{t}} & \text { no support } \\
\sum_{t \in S T} \frac{r 1_{t}}{(1+d r)^{t}}+\sum_{t \notin S T} \frac{r 0_{t}}{(1+d r)^{t}} & 1-\text { sided } C f D \\
\sum_{t \in S T} \frac{r 2_{t}}{(1+d r)^{t}}+\sum_{t \notin S T} \frac{r 0_{t}}{(1+d r)^{t}} & 2-\text { sided } C f D
\end{array}\right.
$$

With: $\quad d r \quad$ Discount rate

This allows us to calculate the effective subsidy ES as follows:

$$
E S=H E R-\sum_{t} \frac{r 0_{t}}{(1+d r)^{t}}
$$

In a final step, we account for the fact that some auction designs pay for grid connection and others put the costs onto the developer. Harmonising the effective subsidy ES by subtracting the grid costs $C G$ accounts for the difference in the auction conditions and happens after the cash-flow analysis. The implied cost differences can be regarded as a significant subsidy $\left(\right.$ see $\left.^{35}\right)$. We have collected wind farm-specific connection costs were available in the overall data table in Supplementary Data and Supplementary Table 1, averaging country-specific data where primary data was missing. In some cases (e.g. Germany) connection costs are given in $€ / \mathrm{kW}$ following the methodology $\mathrm{in}^{35}$, which then can be converted into $€_{2019} / \mathrm{MWh}$ using capacity factors. The UK is the only country where wind farms pay in full for the grid connection. The effective subsidy with grid connection $E S_{\text {GridConn }}$ therefore only applies to the UK auction results, as $E S_{\text {GridConn }}=E S_{U K}$. For all other countries $E S_{N o G r i d C o n n}=E S_{D K, N L, B E, D E}$. The relationship between $E S_{\text {GridConn }}$ and $E S_{\text {NoGridConn }}$ are:

$$
E S_{\text {NoGridConn }}=E S_{\text {GridConn }}-C G
$$

In the results section of the paper, we opt to show results with and without grid connection costs as equally valid options. The discussion on cost recovery of grid infrastructure is to be held at a different occasion. 


\section{Data availability}

520 The datasets used in this study are available in the ZENODO repository as Supplementary Data, DOI: $10.5281 /$ zenodo.3890232 (https://doi.org/10.5281/zenodo.3890232). This includes the raw data for all results presented here and input data for Figures 1-4.

\section{Code availability}

The cashflow model produced for this study is available in the ZENODO repository as

DOI:

10.5281/zenodo.3733605

(https://doi.org/10.5281/zenodo.3733605). The model is set up to recreate results of this paper. Please refer to the README in the instructions.

\section{References}

530 1. IRENA. Renewable Energy Capacity Statistics 2020. (2020).

2. IEA. World Energy Outlook 2019. (OECD, 2019). doi:10.1787/caf32f3b-en

3. European Commission. A Clean Planet for all: A European long-term strategic vision for a prosperous, modern, competitive climate neutral economy - In-Depth Analysis in Support of the Commission (Communication Com (2018) 773). (2018).

4. Bosch, J., Staffell, I. \& Hawkes, A. D. Temporally-explicit and spatially-resolved global onshore wind energy potentials. Energy (2017). doi:10.1016/j.energy.2017.05.052

5. Arent, D. et al. Improved Offshore Wind Resource Assessment in Global Climate Stabilization Scenarios. (2012). doi:10.2172/1055364

6. Toke, D. The UK offshore wind power programme: A sea-change in UK energy policy? Energy Policy 39, 526-534 (2011).

7. Green, R. \& Vasilakos, N. The economics of offshore wind. Energy Policy 39, 496-502 (2011).

8. PwC. Unlocking Europe's offshore wind potential. Moving towards a subsidy free industry. (2018).

9. Aurora Energy Research. The new economics of offshore wind. (2018).

10. NewEnergyUpdate. Offshore wind developers see ripe conditions for zero-subsidy bids. New Energy Update (2018). Available at: http://newenergyupdate.com/wind-energyupdate/offshore-wind-developers-see-ripe-conditions-zero-subsidy-bids. 
11. Creutzig, F. et al. The underestimated potential of solar energy to mitigate climate change. Nat. Energy 2, 17140 (2017).

12. Schmidt, O., Hawkes, A., Gambhir, A. \& Staffell, I. The future cost of electrical energy storage based on experience rates. Nat. Energy 2, 17110 (2017).

13. Heptonstall, P., Gross, R., Greenacre, P. \& Cockerill, T. The cost of offshore wind: Understanding the past and projecting the future. Energy Policy 41, 815-821 (2012).

14. Vieira, M., Snyder, B., Henriques, E. \& Reis, L. European offshore wind capital cost trends up to 2020. Energy Policy 129, 1364-1371 (2019).

15. Dismukes, D. E. \& Upton, G. B. Economies of scale, learning effects and offshore wind development costs. Renew. Energy 83, 61-66 (2015).

16. Bolinger, M. \& Wiser, R. Understanding wind turbine price trends in the U.S. over the past decade. Energy Policy 42, 628-641 (2012).

17. Wiser, R. et al. Expert elicitation survey on future wind energy costs. Nat. Energy 1, 16135 (2016).

18. Hoffman, C. S. Financial Viability of Offshore Wind on the Texas Gulf Coast. (The University of Texas at Austin, 2019).

19. Klinge Jacobsen, H., Hevia-Koch, P. \& Wolter, C. Nearshore and offshore wind development: Costs and competitive advantage exemplified by nearshore wind in Denmark. Energy Sustain. Dev. 50, 91-100 (2019).

20. Beiter, P., Musial, W., Kilcher, L., Maness, M. \& Smith, A. An Assessment of the Economic Potential of Offshore Wind in the United States from 2015 to 2030. (2017). doi:10.2172/1349721

21. Noonan, M. et al. IEA Wind Wind Technology Collaboration Programme Task 26: Offshore Wind Energy International Comparative Analysis. (2018).

22. Lazard. Lazard's levelized cost of storage analysis - version 12.0. Lazard (2018).

23. OWPB. Transmission Costs for Offshore Wind Final Report April 2016. (2016).

57524 Algemene Rekenkamer. Focus on the cost of offshore wind energy. (2018).

25. Aldersey-Williams, J., Broadbent, I. D. \& Strachan, P. A. Better estimates of LCOE from audited accounts - A new methodology with examples from United Kingdom offshore wind and CCGT. Energy Policy 128, 25-35 (2019).

26. Kitzing, L. Risk Implications of Energy Policy Instruments. (Department of Management Engineering, Technical University of Denmark, 2014).

27. EWEA. Design options for wind energy tenders. (2015).

28. Fitch-Roy, O. An offshore wind union? Diversity and convergence in European offshore wind governance. Clim. Policy 16, 586-605 (2016).

29. Grothe, O. \& Müsgens, F. The influence of spatial effects on wind power revenues under direct marketing rules. Energy Policy 58, 237-247 (2013).

30. Partridge, I. Cost comparisons for wind and thermal power generation. Energy Policy 112, 272-279 (2018). 
31. Aldersey-Williams, J. \& Rubert, T. Levelised cost of energy - A theoretical justification and critical assessment. Energy Policy 124, 169-179 (2019).

32. Heptonstall, P., Steiner, F. \& Gross, R. The costs and impacts of intermittency - 2016 update - A UKERC TPA report. (2017).

33. Cleijne, H. Cost of offshore transmission. DNV GL (2019). Available at: https://www.tennet.eu/fileadmin/user_upload/Company/News/Dutch/2019/20190624_ DNV_GL_Comparison_Offshore_Transmission_update_French_projects.pdf.

34. Hundleby, G. Dong's Borssele Costs - a landmark Dutch auction by Giles Hundleby. BVG Associates (2016). Available at: https://bvgassociates.com/dongs-borssele-costs/.

35. Müsgens, F. \& Riepin, I. Is Offshore Already Competitive? Analyzing German Offshore Wind Auctions. in 2018 15th International Conference on the European Energy Market (EEM) 1-6 (IEEE, 2018). doi:10.1109/EEM.2018.8469851

36. Egli, F., Steffen, B. \& Schmidt, T. S. A dynamic analysis of financing conditions for renewable energy technologies. Nat. Energy 3, 1084-1092 (2018).

37. BEIS. Energy and emissions projections. (2019). Available at: https://www.gov.uk/government/collections/energy-and-emissions-projections.

38. WindEurope. Wind energy in Europe in 2018 - Trends and statistics. (2018). Available at: https://windeurope.org/wp-content/uploads/files/about-wind/statistics/WindEuropeAnnual-Statistics-2018.pdf.

39. reNews. Home - reNews - Renewable Energy News. reNews (2019). Available at: https://renews.biz/.

40. 4COffshore. Home - 4C Offshore Website. 4COffshore (2019). Available at: https://www.4coffshore.com/.

41. OffshoreWind.biz. Home - OffshoreWind.biz. OffshoreWind.biz (2019). Available at: https://www.offshorewind.biz/.

42. WindPowerOffshore. Home - Offshore wind power projects \& companies. Windpower Offshore (2019). Available at: https://www.windpoweroffshore.com/.

43. RenewablesNow. Home - Renewable energy news \&amp; research. RenewablesNow (2019). Available at: https://renewablesnow.com/.

44. Pfenninger, S. \& Staffell, I. Long-term patterns of European PV output using 30 years of validated hourly reanalysis and satellite data. Energy 114, 1251-1265 (2016).

45. Staffell, I. \& Pfenninger, S. Using bias-corrected reanalysis to simulate current and future wind power output. Energy 114, 1224-1239 (2016).

46. Aldersey-Williams, J., Broadbent, I. D. \& Strachan, P. A. Analysis of United Kingdom offshore wind farm performance using public data: Improving the evidence base for policymaking. Util. Policy 62, (2020).

47. Smith, A. Offshore Wind Capacity Factors. (2020). Available at: https://energynumbers.info/. (Accessed: 24th January 2020)

48. Saint-Drenan, Y.-M. et al. A parametric model for wind turbine power curves incorporating environmental conditions. Renew. Energy (2020). 
doi:10.1016/j.renene.2020.04.123

49. Staffell, I. \& Green, R. How does wind farm performance decline with age? Renew. Energy 66, 775-786 (2014).

50. Olauson, J., Mikael, B., Edström, P. \& Carlstedr, N.-E. Wind turbine performance decline in Sweden. Wind Energy 20, (2017).

51. Porté-Agel, F., Bastankhah, M. \& Shamsoddin, S. Wind-Turbine and Wind-Farm Flows: A Review. Boundary-Layer Meteorol. 174, 1-59 (2020).

52. Zeng, Z. et al. A reversal in global terrestrial stilling and its implications for wind energy production. Nat. Clim. Chang. 9, 979-985 (2019).

53. Hdidouan, D. \& Staffell, I. The impact of climate change on the levelised cost of wind energy. Renew. Energy 101, 575-592 (2017).

54. Ziegler, L. Assessment of monopiles for lifetime extension of offshore wind turbines Thesis. (Norwegian University of Science and Technology, 2018).

55. Geuss, M. Offshore, Act Two: New owner repowers 20-year-old wind farm off Swedish coast. Ars Technica (2018). Available at: https://arstechnica.com/informationtechnology/2018/12/offshore-act-two-new-owner-repowers-20-year-old-wind-farmoff-swedish-coast/.

56. Smith, P., Costa-Ros, M., Lange, B., Stiesdal, H. \& Pollicino, F. Question of the Week: Are offshore projects built to last? Windpower Monthly (2014). Available at: https://www.windpowermonthly.com/article/1320109/question-week-offshoreprojects-built-last.

57. Foxwell, D. Research claims 30-year lifespan is within reach for offshore wind projects. Riviera Maritime Media (2017). Available at: https://www.rivieramm.com/news-contenthub/research-claims-30-year-lifespan-is-within-reach-for-offshore-wind-projects28324.

58. Kolios, A. \& Martínez Luengo, M. The end of the line for today's wind turbines Renewable Energy Focus. Renewable Energy Focus (2016). Available at: http://www.renewableenergyfocus.com/view/43817/the-end-of-the-line-for-today-swind-turbines/.

59. Wiese, F. et al. Open Power System Data - Frictionless data for electricity system modelling. Appl. Energy 236, 401-409 (2019).

60. ENTSO-E. ENTSO-E Transparency Platform. (2019). Available at: https://transparency.entsoe.eu/.

61. Capros, P. et al. EU Reference Scenario 2016. European Commission (2016). doi:10.2833/9127

62. Twomey, P. \& Neuhoff, K. Wind power and market power in competitive markets. Energy Policy 38, 3198-3210 (2010).

63. Engelhorn, T. \& Müsgens, F. How to estimate wind-turbine infeed with incomplete stock data: A general framework with an application to turbine-specific market values in Germany. Energy Econ. 72, 542-557 (2018).

64. Collins, S., Deane, P., Ó Gallachóir, B., Pfenninger, S. \& Staffell, I. Impacts of Inter-annual 
Wind and Solar Variations on the European Power System. Joule 2, 2076-2090 (2018).

\section{Author contributions}

MJ, FM, IS and IR conceived the study and developed the analysis. All authors contributed to data gathering and data analysis. All authors wrote and edited the paper.

\section{Competing interests}

The authors declare no competing financial or non-financial interests. 